\title{
Description of two endangered new seasonal killifish species of the genus Cynolebias from the São Francisco River basin, Brazilian Caatinga (Cyprinodontiformes, Aplocheilidae)
}

\author{
Wilson J. E. M. Costa ${ }^{1}$ \\ 21941-971, Rio de Janeiro, Brazil \\ http://zoobank.org/BE9AD048-B85E-4334-B839-E8496AF6A541 \\ Corresponding author: Wilson J. E. M. Costa (wcosta@acd.ufrj.br)
}

1 Laboratory of Systematics and Evolution of Teleost Fishes, Institute of Biology, Federal University of Rio de Janeiro, Caixa Postal 68049, CEP

\begin{abstract}
Received 10 September 2017

Accepted 19 September 2017

Published 12 October 2017

Academic editor:

Peter Bartsch

\section{Key Words}

Biodiversity

conservation

systematics

taxonomy

trophic specialisations

Two new species of Cynolebias are described from temporary pools of the Verde Grande River drainage, São Francisco basin, in the semiarid Caatinga, a phytogeographical province of northeastern Brazil. Cynolebias elegans sp. n., a member of the $C$. gilbertoi group, is considered as the smallest species of the genus, reaching about $38 \mathrm{~mm}$ of standard length; it is distinguished from all other species of the group by the long unpaired fins, relative position of anal fin and vertebrae, and morphometric data. Cynolebias gorutuba sp. n. belongs to the Cynolebias zeta-clade, a group of large species supposedly feeding on smaller sympatric seasonal killifishes; it differs from other species of the group by the female colour pattern, relative position of dorsal fin and vertebrae, and cephalic neuromast pattern. Both species herein described were not found in recent collecting trips, after their habitats had been drastically modified, and are also possibly highly endangered if not already extinct. Field data relative to gradual habitat decline in the type locality region of C. elegans indicate that after pools lose the dense vegetation that provides shelter to small species, these species such as $C$. elegans become exposed to larger sympatric predatory species and are extirpated. These data support the hypothesis that small seasonal killifish species specialised in living within marginal shaded areas of temporary pools are more susceptible to environmental changes than other congeners.
\end{abstract}

\section{Introduction}

A great diversity of killifishes that only inhabit temporary pools formed during rainy seasons has been reported for the Caatinga, the semiarid phytogeographical province of northeastern Brazil (e.g., Costa and Brasil 1991, 1993; Costa 2001, 2007, 2014; Costa et al. 2012, 2014). In most of the Caatinga region, often there are two seasonal killifish generations per year, one during the first rains after a long dry period, usually between November and January, and another between February and April. However, rains may be very irregular and some areas may remain dry for a year or more. In dry periods pools disappear and species survive through drought resistant eggs in diapause stage (Wourms 1972). This specialised life cycle style, occurring in several South American and African aplocheilid killifishes, is often known as annualism (e.g., Costa 1998a).

Two genera of seasonal killifishes occur in the Caatinga, Cynolebias Steindachner, 1876 and Hypsolebias Costa, 2006. Diversification of these genera has been estimated to have started during the Miocene, after the climate became drier (Costa et al. 2017). Cynolebias has been divided in two subgenera, Bathylebias Costa, 2008, with a single species endemic to the seasonal dry forest of the Paranã valley in central Brazil, and Cynolebias, 
comprising 16 species endemic to the Caatinga of northeastern Brazil (Costa 2001, 2008, 2014). Members of the latter subgenus are unique among Neotropical killifishes in having males that produce sounds during courtship behaviour (Belote and Costa 2003; Costa et al. 2010), using a morphologically complex pharyngeal apparatus (Costa 2009a). In contrast to most aplocheilid killifishes that are small, usually not surpassing $80 \mathrm{~mm}$ of standard length (SL), some species of Cynolebias often reach between 100 and $120 \mathrm{~mm} \mathrm{SL}$, and supposedly prey on small sympatric seasonal killifishes (Costa 2001).

All species of Cynolebias, except C. porosus Steindachner, 1876, were described after 1990 as a result of frequent recent efforts to sample the temporary pools of the Brazilian seasonal dry forests (e.g., Costa et al. 1990; Costa and Brasil 1991, 1993; Costa 2001, 2014; Costa et al. 2010). The subgenus Cynolebias has been divided in three species groups (e.g., Costa 2014), the C. gilbertoi, C. porosus and C. perforatus groups. Both the C. gilbertoi and C. perforatus groups are endemic to the São Francisco River basin, whereas the $C$. porosus group encompasses species endemic to most river basins of the Caatinga. Among species of the $C$. perforatus group, a clade including all species except $C$. rectiventer, the $C y$ nolebias zeta-clade (Costa 2001), is the most diversified group of the genus. A new species of the C. gilbertoi group and another of the Cynolebias zeta-clade (hereafter CZC) were first collected in 2002 and 2005, respectively. Subsequent field studies showed that their habitats were drastically modified and they were not found in most recent field surveys. In the present study, descriptions of the new species and records of habitat decline for the last 15 years are provided.

\section{Material and methods}

Specimens were captured with small dip nets and fixed in formalin for a period of 10 days, and then transferred to $70 \%$ ethanol. Collections were made with permits provided by ICMBio (Instituto Chico Mendes de Conservação da Biodiversidade). Material is deposited in Instituto de Biologia, Universidade Federal do Rio de Janeiro, Rio de Janeiro (UFRJ). Descriptions of colouration of living exemplars were based on observations just after collections, in small transparent plastic bottles. Type specimens were photographed live six hours after collection. Measurements and counts follow Costa (1988). Measurements are presented as percentages of standard length (SL), except for those related to head morphology, which are expressed as percentages of head length. Fin-ray counts include all elements. Osteological preparations followed Taylor and Van Dyke (1985); the abbreviation C\&S in lists of material indicates those specimens that were cleared and stained for osteological examination. Terminology for osteological structures followed Costa (2006), for frontal squamation Hoedeman (1958), and for cephalic neuromast series Costa (2001).

\section{Results}

\section{Cynolebias elegans sp. $n$.}

http://zoobank.org/8AE1FA2B-9D3F-4E69-968A-4EF6F967779B Figs 1-2, Table 1

Holotype. UFRJ 9431, male, $36.1 \mathrm{~mm}$ SL; Brazil: Bahia state: Pindaí municipality: temporary pool close to road BR122 , about $8 \mathrm{~km} \mathrm{~S}$ of the village of Pindaí, Mata Veado Creek floodplains, Verde Grande River drainage, São Francisco River basin, 14'33'39' S 4242'10' W, altitude about 630 $\mathrm{m}$ asl; W. J. E. M. Costa and C. P. Bove, 15 January 2005.

Paratypes. UFRJ 9350, 1 male, $37.6 \mathrm{~mm} \mathrm{SL,} 1$ female, $35.1 \mathrm{~mm}$ SL; UFRJ 6890, 2 males, 36.8-37.9 mm SL, 1 female, $36.9 \mathrm{~mm}$ SL (C\&S); collected with holotype.

Diagnosis. Cynolebias elegans is similar to other species of the $C$. gilbertoi group (C. gilbertoi Costa, 1998 and $C$. ochraceus Costa, 2014) and distinguished from all other congeners of the subgenus Cynolebias, by the following character states: numerous vomerine teeth (9-16 vs. 1-4, when teeth are present), 7-8 gill-rakers on the ventral part of the first branchial arch (vs. 9-12), highest body depth at vertical just anterior to pelvic-fin base (vs. through pectoral-fin base), and presence of light dots on flank arranged in vertical groups (vs. light dots when present not arranged in vertical groups). Cynolebias elegans differs from $C$. gilbertoi and $C$. ochraceus by having long dorsal and anal fins in males, their extremities excluding filaments posteriorly reaching caudal-fin base (vs. reaching caudal peduncle), greater pre-pelvic length in males (52.2-53.9\% SL, vs. $48.5-49.9 \% \mathrm{SL}$ in $C$. gilbertoi and $48.9-50.5 \% \mathrm{SL}$ in C. ochraceus), and first proximal radial of the anal fin between neural spines of 9th and 10th vertebrae in males, and between neural spines of 11th and 12th vertebrae in females (vs. between neural spines of 11th and 13th vertebrae in males, and between neural spines of 12th and 14th vertebrae in females). Cynolebias elegans is also distinguished from $C$. gilbertoi by having larger head (31.3-34.2 $\%$ SL in males, $32.1-33.4 \%$ in females, vs. $27.9-30.3$ $\% \mathrm{SL}$ in males, $29.0-31.1 \%$ in females) and smaller eye (25.5-29.1\% of head length in males, 27.3-29.9\% in females, vs. $30.0-31.0 \%$ of head length in males, $31.5-34.2$ $\%$ in females); and from C. ochraceus by having fewer vertebrae (31-32 vs. 33-34), more slender body (body depth $32.5-34.5 \%$ SL, vs. $35.0-37.8 \%$ SL), and flank light purplish brown in males (vs. light yellow ochre). The largest specimen examined was $37.9 \mathrm{~mm} \mathrm{SL}$, suggesting that $C$. elegans is the smallest species of the genus.

Description. Morphometric data appear in Table 1. Body relatively deep, compressed. Greatest body depth at vertical just anterior to pelvic-fin base. Dorsal and ventral profiles of head and trunk slightly convex, approximately straight on caudal peduncle. Head moderately wide, sub-triangular in lateral view. Jaws short, teeth numerous, conical, irregularly arranged; outer teeth hypertro- 


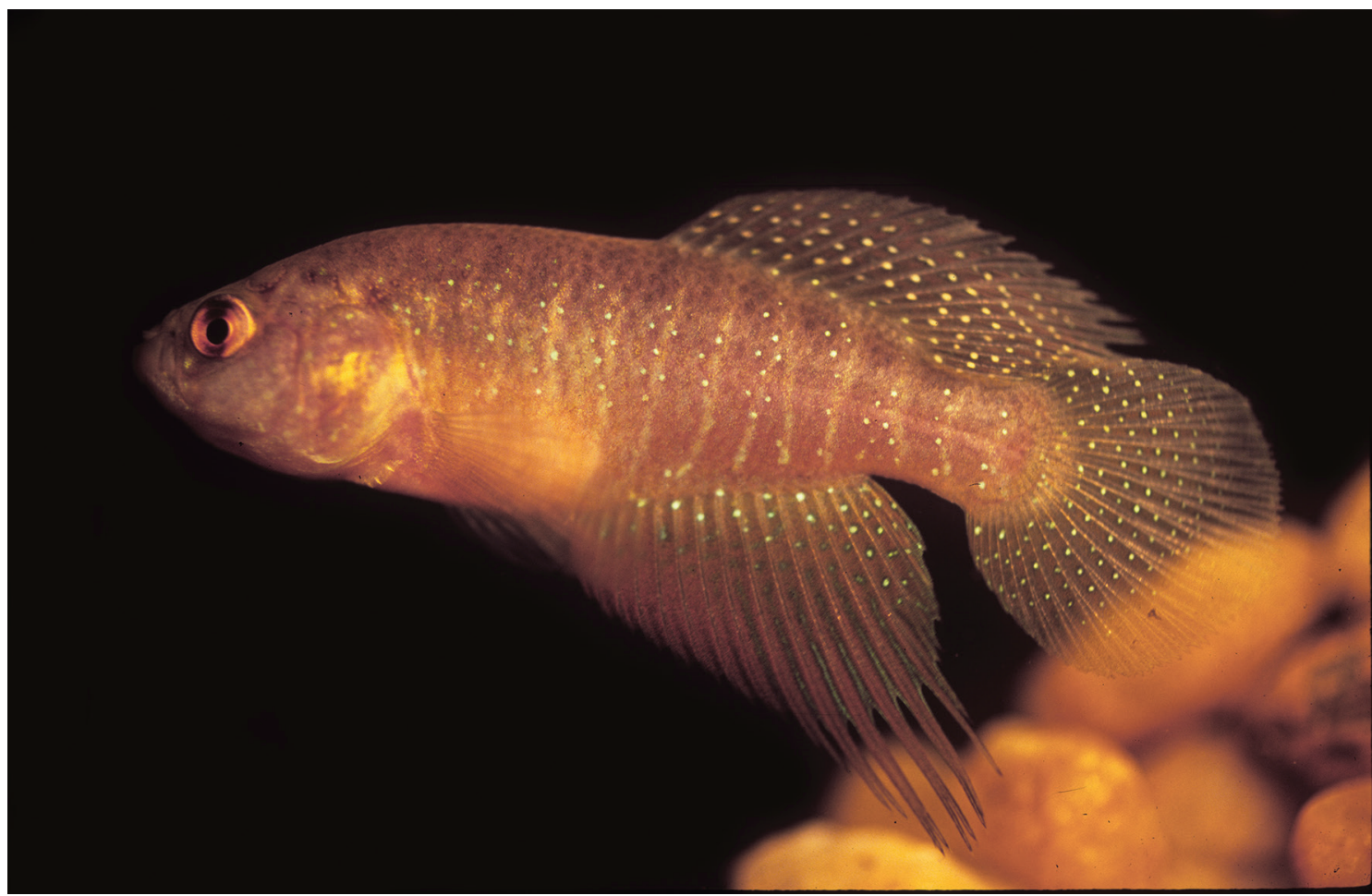

Figure 1. Cynolebias elegans sp. n., live holotype, UFRJ 9431, male, $36.1 \mathrm{~mm}$ SL. Photograph by W.J.E.M. Costa.

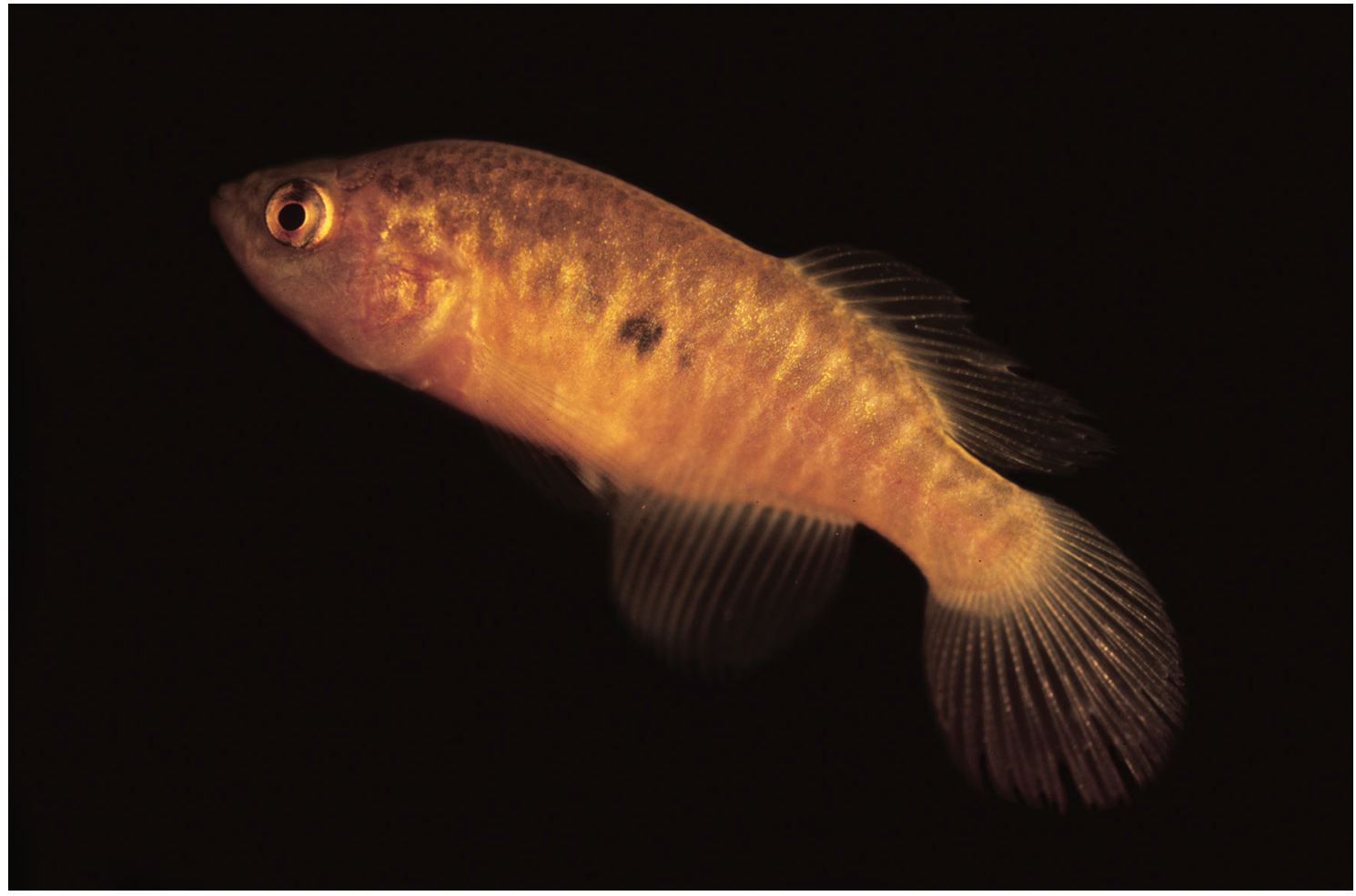

Figure 2. Cynolebias elegans sp. n., live paratype, UFRJ 9350, female, $35.1 \mathrm{~mm}$ SL. Photograph by W.J.E.M. Costa.

phied, inner teeth small and numerous. Vomerine teeth 13. Gill-rakers on first branchial arch $2+7$, gill-rakers short, straight, without denticles.

Dorsal and anal fins relatively long and pointed in males, posteriorly reaching caudal-fin base when excluding fila- ments, rounded in females; in males, short filamentous rays on dorsal-fin extremity, long filamentous rays on anal-fin extremity, posteriorly reaching middle portion of caudal fin; no filamentous rays in females. Caudal fin rounded. Pectoral fin rounded, posterior margin reaching vertical between 
Table 1. Morphometric data of Cynolebias elegans.

\begin{tabular}{l|c|c|c}
\hline \multirow{2}{*}{} & Holotype & \multicolumn{2}{|c}{ Paratypes } \\
\cline { 2 - 4 } & male & males (3) & females (2) \\
\hline Standard length $(\mathrm{mm})$ & 36.1 & $36.8-37.9$ & $35.1-36.9$ \\
\hline Percent of standard length \\
\hline Body depth & 34.0 & $32.5-34.5$ & $33.0-33.1$ \\
\hline Caudal peduncle depth & 15.1 & $14.2-15.7$ & $14.3-15.4$ \\
\hline Pre-dorsal length & 59.3 & $56.7-59.5$ & $63.0-63.3$ \\
\hline Pre-pelvic length & 53.9 & $52.2-54.2$ & $54.9-55.4$ \\
\hline Length of dorsal-fin base & 31.3 & $29.2-32.8$ & $25.8-27.5$ \\
\hline Length of anal-fin base & 35.5 & $32.2-35.3$ & $26.3-27.3$ \\
\hline Caudal-fin length & 39.0 & $34.9-38.8$ & $33.6-37.9$ \\
\hline Pectoral-fin length & 32.3 & $28.3-30.9$ & $28.2-29.4$ \\
\hline Pelvic-fin length & 9.8 & $8.3-10.1$ & $9.6-10.2$ \\
\hline Head length & 34.2 & $31.3-32.9$ & $32.1-33.4$ \\
\hline Percent of head length & \multicolumn{3}{|l}{} \\
\hline Head depth & 93.5 & $94.4-98.2$ & $91.9-97.6$ \\
\hline Head width & 74.1 & $71.6-78.1$ & $75.0-75.6$ \\
\hline Snout length & 14.5 & $14.0-15.5$ & $13.9-14.5$ \\
\hline Lower jaw length & 20.7 & $19.5-22.6$ & $19.2-19.4$ \\
\hline Eye diameter & 26.6 & $25.5-29.1$ & $27.3-29.9$ \\
\hline
\end{tabular}

base of 5th and 6th anal-fin rays in males, reaching base of 3rd anal-fin ray in females. Pelvic fin small, tip reaching between base of 3rd and 4th anal-fin rays in males, reaching base of 2nd anal-fin ray in females; pelvic-fin bases medially separated by short interspace. Dorsal-fin origin at vertical between base of 3rd and 5th anal-fin rays in males, through base of 3rd anal-fin ray in females. Dorsal-fin rays 17-18 in males, 16-17 in females; anal-fin rays 18-20 in males, 18-19 in females; caudal-fin rays 28-29; pectoral-fin rays 12 ; pelvic-fin rays 6 . In males, papillate contact organs on inner surface of three or four dorsal-most pectoral-fin rays. Second proximal radial of dorsal fin between neural spines of 12th and 13th vertebrae in males, between neural spines of 13th and 14th vertebrae in females; first proximal radial of anal fin between pleural ribs of 9th and 10th vertebrae in males, between pleural ribs of 11th and 12th vertebrae in females; total vertebrae 31-32.

Scales small, cycloid. Body and head entirely scaled, except anterior ventral surface of head. Body squamation extending over anterior $25 \%$ of caudal-fin base; no scales on dorsal, anal and pectoral-fin bases. Scales irregularly arranged on frontal region and trunk. Longitudinal series of scales 34-36; transverse series of scales 13-14; scale rows around caudal peduncle 22 . No contact organs on scales. Cephalic neuromasts: supraorbital 25-30; parietal 4; anterior rostral 2, posterior rostral 2; infraorbital $5+$ 31-33; preorbital 3-4; otic 5, post-otic 7-8; supratemporal 2-3; median opercular $1-3$, ventral opercular 5-8; pre-opercular plus mandibular 45-47; lateral mandibular 3-4+8-9, paramandibular 1 .

Colouration in life. Males. Flank light purplish brown, with 10 or 11 lighter pale golden brown bars and minute white dots arranged in vertical zones. Dorsum pale purplish brown, venter white. Head pale purplish brown, with dark grey dots on otic, post-otic and supra-temporal neuromasts; golden iridescence on opercular region. Iris yellow, with dark brown bar through orbit centre. Dorsal and caudal fin light grey, with white dots. Anal fin pale pink, basal portion with white dots; filaments pale pink. Pelvic fin pale pink. Pectoral fin hyaline.

Females. Flank light purplish brown, with 11 or 12 pale golden brown bars; 1-2 black spots on centre of flank. Dorsum pale purplish brown, venter white. Head pale purplish brown, with dark grey dots on otic, post-otic and supra-temporal neuromasts; pale golden iridescence on opercular region. Iris yellow, with dark brown bar through orbit centre. Fins hyaline.

Colouration in alcohol. Similar to colouration in life, dark marks still distinct, but paler ; white dots on trunk and fins and pink pigmentation on anal and pelvic fins of males, and golden iridescence on opercular region of both sexes inconspicuous.

Distribution and conservation. Cynolebias elegans is known from a single locality, a temporary pool in the Verde Grande River drainage, Bahia, Brazil (14'33'39" $\mathrm{S} 42^{\circ} 42^{\prime} 10^{\prime} \mathrm{W}$, altitude about $630 \mathrm{~m}$ asl). This pool was first explored in January 2002, when the only species found was Hypsolebias mediopapillatus (Costa, 2006). At that time, the pool was densely covered by aquatic vegetation and marginal spiny bushes, making it difficult to access the pool, except in its portion closer to the road. During a second visit, January 2005, cattle were introduced in the area and original vegetation was substituted by grass. Both C. oticus and H. mediopapillatus were abundant, but only six specimens of $C$. elegans (the type series) and one of Hypsolebias fulminantis (Costa \& Brasil, 1993) were collected. In several other pools found along the road, many specimens of $C$. oticus, C. leptocephalus and $H$. mediopapillatus were found, but both $C$. elegans and $H$. fulminantis were absent. The type locality and neighbouring pools were sampled again in May 2009 and January 2010, but no specimen of C. elegans was found. New visits occurred in January and May 2017, but the type locality was now highly modified into a permanent pool containing only small not identified Characiformes. These field records indicate that $C$. elegans is a rare, critically endangered species, if not already extinct.

Etymology. From the Latin elegans (elegant, fine), an allusion to the distinctive general appearance of the new species, with males combing relatively slender body with long unpaired fins.

\section{Cynolebias gorutuba sp. n.}

http://zoobank.org/5B48F085-807C-46BE-B11E-8E32B11FBE96 Figs 3-4, Table 2

Holotype. UFRJ 6789, male, $88.8 \mathrm{~mm}$ SL; Brazil: Minas Gerais state: Janaúba municipality: temporary pool near road MG-401, floodplains of Gorutuba River, 
Table 2. Morphometric data of Cynolebias gorutuba.

\begin{tabular}{l|c|c|c}
\hline \multirow{2}{*}{} & Holotype & \multicolumn{2}{|c}{ Paratypes } \\
\cline { 2 - 4 } & male & males (2) & females (2) \\
\hline Standard length (mm) & 88.8 & $50.7-83.9$ & $42.0-50.1$ \\
\hline Percent of standard length & 33.1 & $30.0-31.3$ & $27.8-29.4$ \\
\hline Body depth & 14.2 & $12.5-14.1$ & $12.5-13.0$ \\
\hline Caudal peduncle depth & 60.0 & $61.3-65.0$ & $63.7-67.5$ \\
\hline Pre-dorsal length & 48.6 & $52.2-53.4$ & $52.4-55.2$ \\
\hline Pre-pelvic length & 27.1 & $23.6-24.9$ & $19.8-21.2$ \\
\hline Length of dorsal-fin base & 34.3 & $27.3-27.9$ & $23.9-24.2$ \\
\hline Length of anal-fin base & 30.0 & $29.2-30.8$ & $30.0-30.8$ \\
\hline Caudal-fin length & - & $22.6-23.0$ & $23.4-23.5$ \\
\hline Pectoral-fin length & 8.0 & $7.3-7.6$ & $7.8-8.4$ \\
\hline Pelvic-fin length & 32.3 & $32.0-33.7$ & $33.8-34.2$ \\
\hline Head length & & \multicolumn{3}{|l}{} \\
\hline Percent of head length & 96.0 & $82.0-92.4$ & $81.9-82.7$ \\
\hline Head depth & 67.3 & $64.5-67.7$ & $65.1-69.9$ \\
\hline Head width & 13.9 & $14.0-15.4$ & $13.3-14.5$ \\
\hline Snout length & 30.0 & $25.8-28.9$ & $23.1-26.5$ \\
\hline Lower jaw length & 19.3 & $18.1-22.6$ & $23.2-25.9$ \\
\hline Eye diameter & & \multicolumn{3}{|l}{} \\
\hline
\end{tabular}

Verde Grande River drainage, São Francisco River basin, $15^{\circ} 47^{\prime} 57^{\prime}$ 'S, 4319' $18^{\prime \prime} \mathrm{W}$, altitude about $525 \mathrm{~m}$ asl; W. J. E. M. Costa et al., 29 January 2010.

Paratypes. UFRJ 9447, 1 female, $50.1 \mathrm{~mm} \mathrm{SL;} \mathrm{UFRJ}$ 9448, 2 males, 50.7-83.9 mm SL, 1 female, 42.0 mm SL (C\&S); same area as holotype, 1548'06”'S, 4319'14”'W, altitude about $525 \mathrm{~m}$ asl; W. J. E. M. Costa, C. P. Bove \& B. B. Costa, 16 January 2016.

Diagnosis. Cynolebias gorutuba is similar to other species of CZC (C. altus Costa, 2001, C. attenuatus Costa, 2001, C. gibbus Costa, 2001, C. leptocephalus Costa \& Brasil, 1993, C. parietalis Costa, 2014, C. perforatus Costa \& Brasil, 1991, C. oticus Costa, 2014), and distinguished from all other congeners, by the following character states: contact organs distributed on the inner surface of entire pectoral fin of males (vs. restricted to the dorsal portion of the fin), trunk scales extending over dorsal-fin base (vs. not extending), scales extending over one third or more of caudal-fin base (vs. about one fourth), and gill-rakers of first branchial arch bowed and with numerous denticles on its surface (vs. straight to slightly curved, usually without denticles, or one or two when present). Cynolebias gorutuba is distinguished from all other species of CZC by the presence of small round dark grey spots on dorsolateral portion of the trunk in females (vs. absence) and by the second proximal radial of dorsal fin between neural spines of 16th and 18th vertebrae in males (vs. between neural spines of 14th and 16th vertebrae); it is also distinguished from all other species of the Cynolebias zeta-clade, except $C$. oticus, by having more preopercular neuromasts (75-87 vs. 53-72). Cynolebias gorutuba also differs from $C$. oticus by having the anterior lateral profile of the body convex (vs. without a concavity on the head), otic and post-otic neuromast series separated (vs. united), more vertebrae (37-38 vs. 35-36), and absence of bars on the flank in males above $75 \mathrm{~mm}$ SL (vs. presence), and from C. parietalis and C. perforatus by fewer caudal-fin rays (30-31 vs. 33-35).

Description. Morphometric data appear in Table 2. Body relatively deep, sub-cylindrical anteriorly, slightly deeper than wide, compressed posteriorly. Greatest body depth at vertical through pectoral-fin base. Dorsal and ventral profiles of head and trunk slightly convex, nearly straight on caudal peduncle. Head moderately wide, sub-triangular in lateral view. Jaws moderately long, teeth numerous, conical, irregularly arranged; outer teeth hypertrophied, inner teeth small and numerous, tip slightly curved inside mouth. Vomerine teeth absent. Gill-rakers on first branchial arch $3+9$, gill-rakers gently bowed, with numerous denticles on distal region.

Dorsal and anal fins short, pointed, and with short filamentous rays in males, rounded and without filaments in females. Caudal fin rounded. Pectoral fin rounded, posterior margin reaching vertical urogenital papilla in males, through anus in females. Pelvic fin small, tip reaching base of 1st anal-fin ray; pelvic-fin bases medially separated by short interspace. Dorsal-fin origin at vertical through base of 6th anal-fin ray. Dorsal-fin rays 18-19 in males, 16-17 in females; anal-fin rays 21 in males, 20 in females; caudal-fin rays 30-31; pectoral-fin rays 14-15; pelvic-fin rays 6 . In males, papillate contact organs on whole inner surface of pectoral fin. Second proximal radial of dorsal fin between neural spines of 16th and 18th vertebrae, first proximal radial of anal fin between pleural ribs of 14 th and 15 th vertebrae; total vertebrae $37-38$.

Scales small, cycloid. Body and head entirely scaled, except anterior ventral surface of head. Body squamation extending over anterior third of caudal-fin base; few scales extending over middle portion of dorsal and anal fins; pectoral-fin fin base scaled. Scales irregularly arranged on frontal region and trunk. Longitudinal series of scales 38-41; transverse series of scales 16; scale rows around caudal peduncle 24 . No contact organs on scales. Cephalic neuromasts: supraorbital 42-48; parietal 5-7; anterior rostral 3, posterior rostral 4; infraorbital $6+40$ 48; preorbital 3; otic 11-12, post-otic 9-12; supratemporal 3-5; median opercular 2, ventral opercular 4; preopercular plus mandibular 75-87; lateral mandibular 12-21, paramandibular 1 .

Colouration. Males. Flank and dorsum pale silver, scale margins pale yellow in larger fish, flank pale brown in smaller; three or four pale grey humeral spots. Venter white. Dorsal portion of head pale yellow to pale brown, with reddish brown dots on otic, post-otic and supra-temporal neuromasts; infraorbital and opercular regions pale silver with pale blue and pale golden iridescence. Jaws white. Iris yellow, with dark reddish brown bar through orbit centre. Dorsal and caudal fins light grey, basal portion pale yellow; white dots on whole dorsal fin and dorsal part or most caudal fin. Anal fin light grey, basal por- 


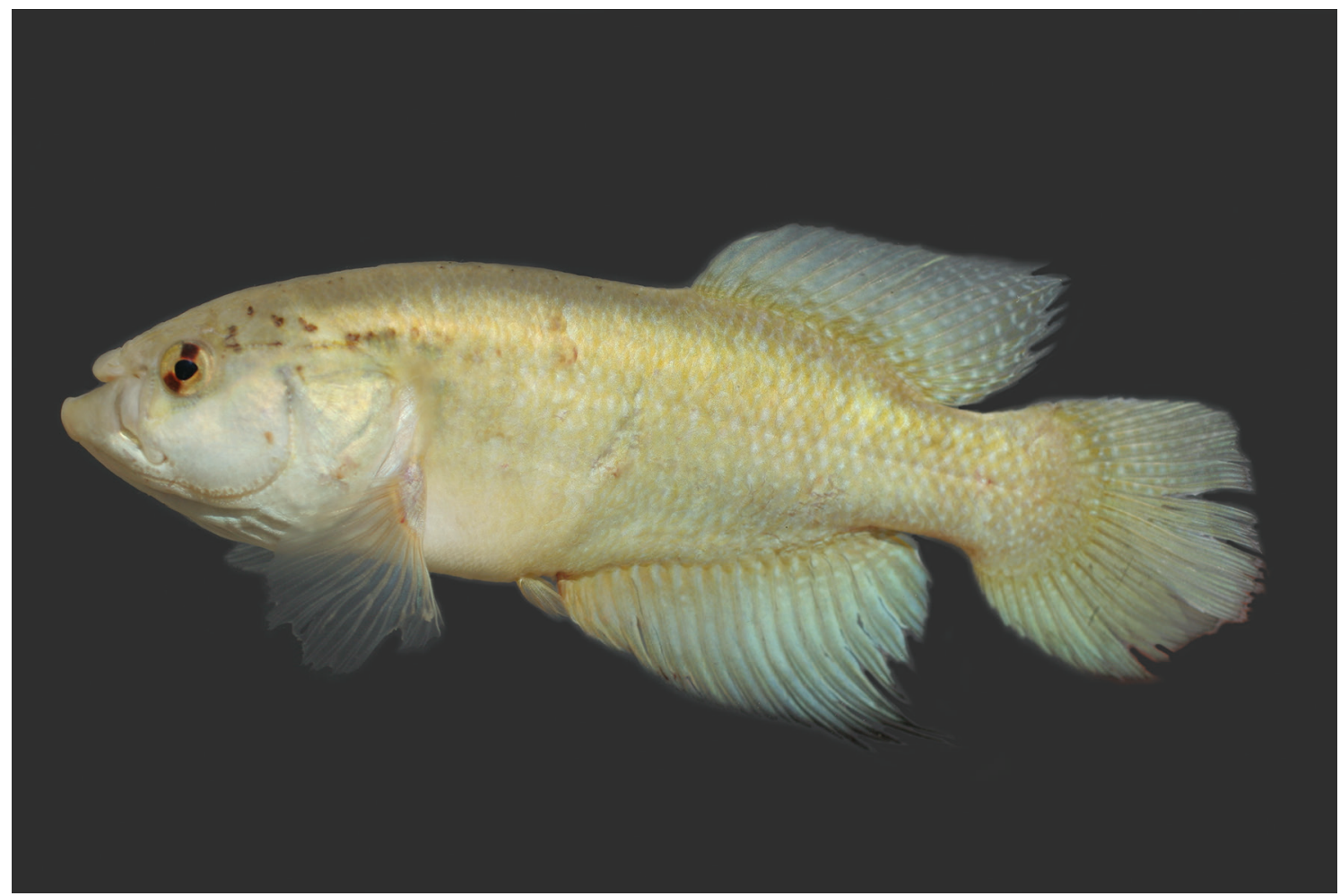

Figure 3. Cynolebias gorutuba sp. n., live holotype, UFRJ 6789, male, 88.8 mm SL. Photograph by W.J.E.M. Costa.

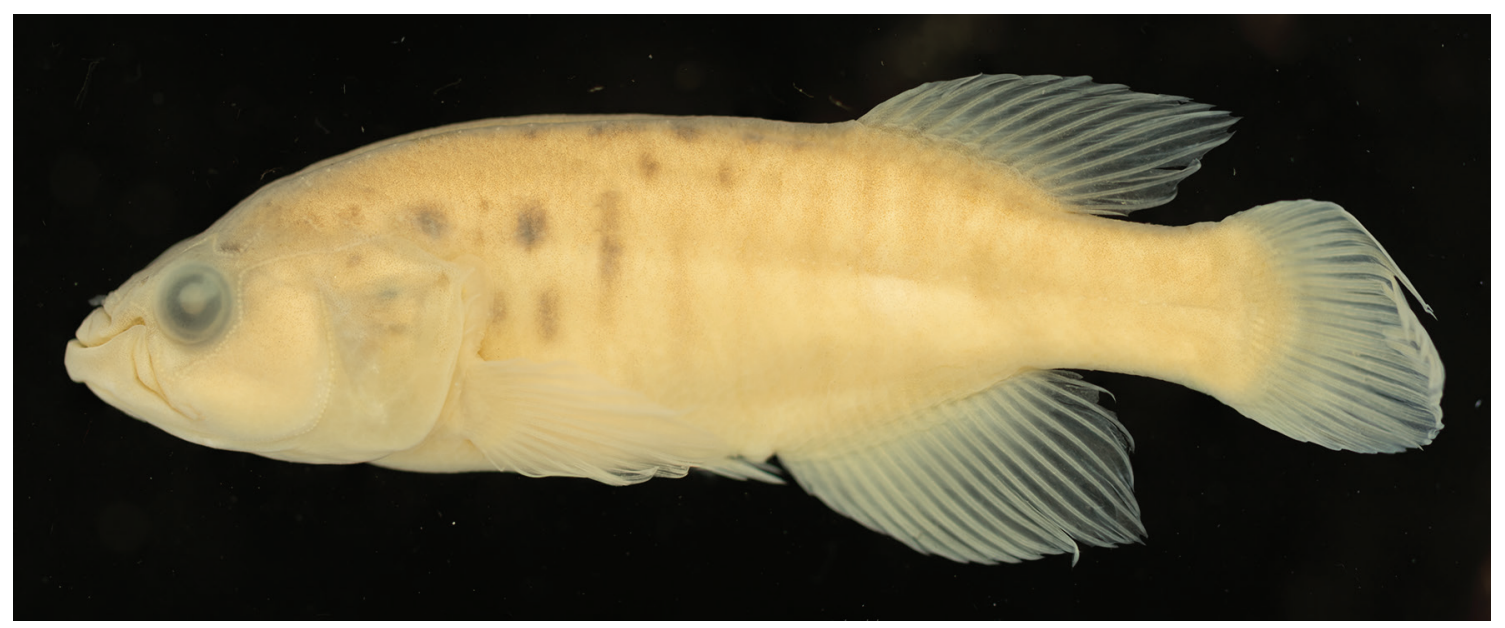

Figure 4. Cynolebias gorutuba sp. n., preserved paratype, UFRJ 9447, female, 50.1 mm SL. Photograph by A. Katz.

tion pale yellow with white dots, filaments black. Pelvic fin pale yellow. Pectoral fin hyaline.

Females. Flank pale brown, with 11 or 12 pale almost inconspicuous grey bars; $2-4$ dark brownish grey spots on humeral region and 4-6 dark grey round spots on dorsolateral portion of trunk. Dorsum pale brown, venter white. Head pale brown, with dark grey dots on otic, post-otic and supra-temporal neuromasts; pale golden iridescence on opercular region. Iris yellow, with dark brown bar through orbit centre. Fins hyaline.

Colouration in alcohol. Similar to colouration in life, dark marks still distinct, but paler; white dots on fins of males and golden iridescence on opercular region of both sexes inconspicuous.

Distribution and conservation. Cynolebias gorutuba is only known from pools in the floodplains of the Gorutuba River, within the town of Janaúba, Minas Gerais, Brazil. This area was first sampled in January 2002, in a vast undisturbed temporary pool with dense aquatic vegetation (1548'06'S, 4319'14'W, altitude about 525 $\mathrm{m}$ asl), when the single species found was Hypsolebias janaubensis (Costa, 2006). In January 2005, the area was visited again, but the whole original pool sampled three years before had been destroyed after expansion of an 
adjacent road. In a few remnant, small pools with very turbid water and no aquatic vegetation, 15 exemplars of $H$. janaubensis and four of C. gorutuba were found. In the third visit, January 2010, pools and typical vegetation had been completely extirped from the area studied before. Searching around this area, some shallow temporary pools were found about $300 \mathrm{~m}$ from the former pool

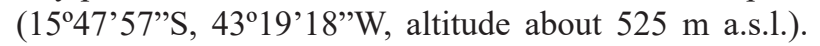
This new area, not visible in previous trips by being covered by dense high vegetation, was then open, with scarce grass, and restricted to shallow turbid water pools. A few specimens of $H$. janaubensis and one of $C$. gorutuba (the holotype) were found. More recently, the area was visited twice, in January and April 2017. No vestige of pools was found in areas previously studied, but within a dense Caatinga forest not distant from the first collecting site, a large temporary pool was found, with about $100 \mathrm{~m}^{2}$ and about $1 \mathrm{~m}$ deep. Hypsolebias janaubensis was common in all parts of the pool, a few exemplars of H. magnificus (Costa \& Brasil, 1991) were found in shaded zones, but no specimen of Cynolebias gorutuba was collected. These field studies suggest that $C$. gorutuba is a rare species, possibly highly threatened with extinction.

Etymology. The name gorutuba refers to the Gorutuba River floodplains, the type locality of $C$. gorutuba. The origin and original meaning of the name is uncertain; local people associate this name to a frog popular name, which needs confirmation.

\section{Discussion}

In a classical paper, Wilson (1985) reported the increasing rate of biodiversity loss contrasting with our incomplete taxonomic knowledge, besides calling attention to the high risk of extinction of organisms inhabiting relatively unexplored habitats, often exhibiting restricted geographical ranges and high levels of specialisation. This was the case of the killifish fauna of the temporary pools of the São Francisco River Basin, where field studies directed to this habitat started only in 1989, when seasonal killifishes of this vast region were still unknown for scientists (Costa and Brasil 1990). At that time, different preservation levels were observed in the Caatinga vegetation, occurring since temporary pools with luxuriant aquatic vegetation highly protected by marginal bushes to pools partially covered by amphibious plants in open vegetation areas used for cattle pasture. Since then, about 40 endemic seasonal killifishes have been described for this region. Costa (2002) first reported habitat decline in the region, recording pools destroyed after implementation of new roads, and Costa et al. (2012) reported several pools recently destroyed by expansion of urban areas and agriculture activities. Although no substantial habitat loss have been recorded in more recent field studies (January and April 2017), the present study illustrates the effects of the biodiversity crisis in the Caatinga, reporting new species that possibly are highly endangered if not already extinct.
This recently known fauna of seasonal killifishes endemic to the Caatinga exhibits diversified morphological patterns and uncommon specialisations (e.g., Costa 2001, 2007, 2009a). The two new species herein described provide a good example of two extreme divergent morphological patterns within the genus Cynolebias. The small size and delicate morphology of $C$. elegans, with relatively long fins in males, contrasts with the robust aspect and short fins of $C$. gorutuba, which is a member of CZC, with species often reaching over $100 \mathrm{~mm} \mathrm{SL}$ or more. Some character states diagnostic for $\mathrm{CZC}$, including gill-rakers of the first branchials arch bowed and with numerous denticles (Costa 2001: fig. 6C) and antero-lateral tip of the lateral process of the sphenotic expanded anteriorly (Costa 2001: fig. 8d), are typical of piscivorous killifishes, suggesting the occurrence of complex trophic relationships among killifishes of the Caatinga. A set of morphological specialisations including large size, long jaws, robust sphenotic bone supporting hypertrophied muscles, and short gill-rakers covered by denticles are only found in the South American Austrolebias elongatus group and in the East African Nothobranchius ocellatus (Seegers, 1985), which are seasonal killifishes reported to prey on smaller sympatric congeners (Costa 2006b, 2009b, 2011, in press).

There is no available data on feeding habits of CZC species. However, field observations highly suggest that they prey on species of the Hypsolebias magnificus group (e.g., H. fulminantis, H. harmonicus, H. magnificus, H. picturatus,) which are small, usually not surpassing $40 \mathrm{~mm} \mathrm{SL}$ (e.g., Costa 2007), and are always found sympatric to CZC species (e.g., C. altus, C. attenuatus, C. leptocephalus, $C$. gorutuba, C. oticus, C. parietalis, C. perforatus). Species of the H. magnificus group are commonly found in shaded parts of temporary pools that are protected by dense bush vegetation (e.g., Costa 2010). In recent pools, just after first rains when all seasonal killifish species are represented by juveniles, species of the H. magnificus group are abundant. In mature seasonal killifish communities, abundance of exemplars of the H. magnificus group seems to depend on the occurrence of CZC species. For example, H. magnificus and H. fulminantis when sympatric to C. parietalis and C. leptocephalus, respectively, in large pools (about $30 \times$ $200 \mathrm{~m}$ ), were restricted to short stretch of the pools densely occupied by the emergent aquatic plant Thalia geniculata L. (Marantaceae) (person. observ.). In February 1999 only four specimens of $H$. picturatus (Costa, 2000) were found in a small area protected by dense aquatic vegetation of a vast temporary pool where Cynolebias altus was abundant. Just after collection, the pool completely dried out, but after March rains, the pools formed again. In May of the same year, numerous adult specimens of $H$. picturatus were found, but no specimen of $C$. altus was collected, indicating that eggs of the latter species did not hatched after that short dry period between rains, allowing H. picturatus be spread in the pool.

Species of the C. gilbertoi group share, among other character states, numerous vomerine teeth, a condition 


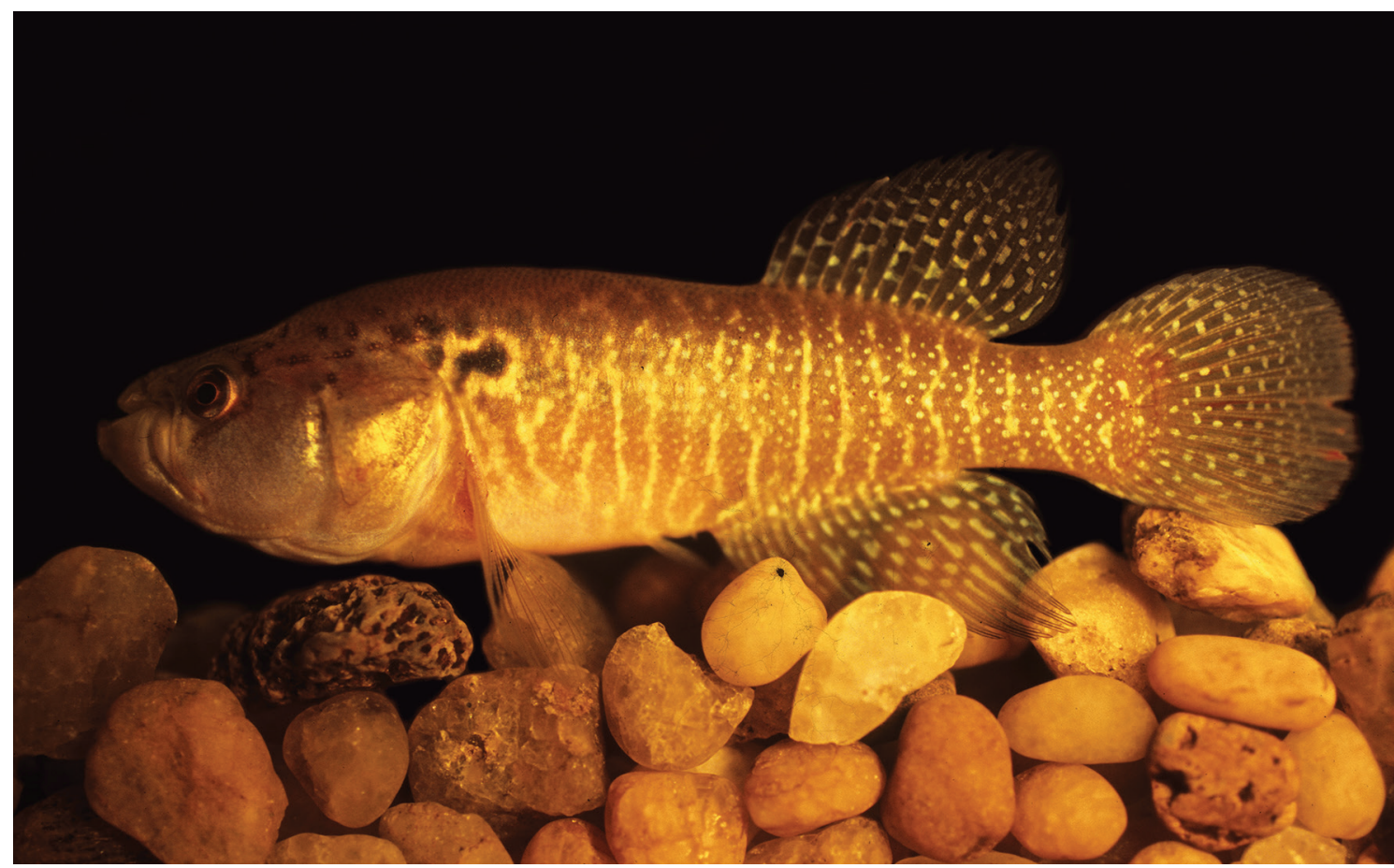

Figure 5. Cynolebias oticus, live paratype, UFRJ 9353, male, $73.5 \mathrm{~mm}$ SL. Photograph by W.J.E.M. Costa.

unique among Cynolebiini killifishes (e.g., Costa 1998b), besides not reaching more than about $60 \mathrm{~mm}$ SL, contrasting with all other congeners that reach about $80 \mathrm{~mm}$ SL or more. The largest size of $C$. elegans here recorded, $37.9 \mathrm{~mm} \mathrm{SL}$, suggests that it is the smallest species of the genus. The few known specimens of $C$. elegans were collected in 2005, just after original vegetation was removed from the pool and around it (see above), but C. oticus was an abundant species. This last species is a typical member of $\mathrm{CZC}$, with predator appearance (Fig. 5), reaching at least about $85 \mathrm{~mm} \mathrm{SL}$ (Costa 2014) and found near the pool bottom. In subsequent field studies (2009 and 2010, see distribution and conservation above), no specimens of C. elegans were found in the region, suggesting that its occurrence depended on the existence of rich aquatic and marginal vegetation, as recorded for its type locality in 2002. Field data thus suggest that in the absence of dense vegetation providing shelter for smaller species such as C. elegans, they became exposed to the larger predatory species $C$. oticus and extirpated from the pool, as recorded in following years. Other species of the C. gilberto group also have been found in pools where original vegetation is kept, corroborating the hypothesis that species of this group are specialised in living in this particular habitat, what makes species of this group more susceptible to environmental changes than other congeners.

\section{Acknowledgements}

I am especially grateful to Claudia Bove and Bruno Costa for accompanying me on most collecting trips. Thanks are also due to Anaïs Barbosa, Axel Katz, and José Leon- ardo Mattos for help on collecting trips, and to A. Katz for taking a photograph of the paratype of $C$. gorutuba. This paper benefited from suggestions provided by P. Bartsch, D. Taphorn and F. Ottoni. This study was supported by CNPq (Conselho Nacional de Desenvolvimento Científico e Tecnológico, Ministério de Ciência e Tecnologia) and FAPERJ (Fundação de Amparo à Pesquisa do Estado do Rio de Janeiro).

\section{References}

Belote DF, Costa WJEM (2003) Reproductive behavior of the Brazilian annual fish Cynolebias albipunctatus Costa \& Brasil, 1991 (Teleostei, Cyprinodontiformes, Rivulidae): a new report of sound production in fishes. Arquivos do Museu Nacional 61: 241-244.

Costa WJEM (1988) Sistemática e distribuição do complexo de espécies Cynolebias minimus (Cyprinodontiformes, Rivulidae), com a descrição de duas espécies novas. Revista Brasileira de Zoologia 5: 557-570. https://doi.org/10.1590/S0101-81751988000400004

Costa WJEM (1998a) Phylogeny and classification of Rivulidae revisited: origin and evolution of annualism and miniaturization in rivulid fishes. Journal of Comparative Biology 3: 33-92.

Costa WJEM (1998b) Cynolebias gilbertoi, a new species of annual fish (Cyprinodontiformes: Rivulidae) from the rio São Francisco basin, northeastern Brazil. Cybium 22: 237-243.

Costa WJEM (2001) The neotropical annual fish genus Cynolebias (Cyprinodontiformes: Rivulidae): phylogenetic relationships, taxonomic revision and biogeography. Ichthyological Exploration of Freshwaters 12: 333-383.

Costa WJEM (2006) Descriptive morphology and phylogenetic relationships among species of the Neotropical annual killifish genera Nematolebias and Simpsonichthys (Cyprinodontiformes: Aplochei- 
loidei: Rivulidae). Neotropical Ichthyology 4: 1-26. http://dx.doi. org/10.1590/S1679-62252006000100001

Costa WJEM (2006b) The South American annual killifish genus Austrolebias (Teleostei: Cyprinodontiformes: Rivulidae): phylogenetic relationships, descriptive morphology and taxonomic revision. Zootaxa 1213: 1-162.

Costa WJEM (2007) Taxonomic revision of the seasonal South American killifish genus Simpsonichthys (Teleostei: Cyprinodontiformes: Aplocheiloidei). Zootaxa 1669: 1-134.

Costa WJEM (2008) Catalog of aplocheiloid killifishes of the world. Reproarte, Rio de Janeiro, 127 pp.

Costa WJEM (2009a) Morphology of the teleost pharyngeal jaw apparatus in the Neotropical annual killifish genus Cynolebias (Cyprinodontiformes: Aplocheiloidei: Rivulidae). Cybium 33: 145-150. http://sfi.mnhn.fr/cybium/numeros/2009/332/13-Costa\%20606.pdf

Costa WJEM (2009b) Trophic radiation in the South American annual killifish genus Austrolebias (Cyprinodontiformes: Rivulidae). Ichthyological Exploration of Freshwaters 20: 179-191.

Costa WJEM (2011) Parallel evolution in ichthyophagous annual killifishes of South America and Africa. Cybium 35: 39-46. http://sfi. mnhn.fr/cybium/numeros/2011/351/05-Costa\%20699.pdf

Costa WJEM (2014) Six new species of seasonal killifishes of the genus Cynolebias from the São Francisco river basin, Brazilian Caatinga, with notes on $C$. porosus. Ichthyological Exploration of Freshwaters 25: 79-96.

Costa WJEM (in press) Comparative morphology, phylogeny, and classification of African seasonal killifishes of the tribe Nothobranchiini (Cyprinodontiformes: Aplocheilidae). Zoological Journal of the Linnean Society.

Costa WJEM, Amorim PF, Bragança PHN (2014) Species limits and phylogenetic relationships of red-finned cryptic species of the seasonal killifish genus Hypsolebias from the Brazilian semi-arid Caatinga (Teleostei: Cyprinodontiformes: Rivulidae). Journal of Zoological Systematics and Evolutionary Research 52: 52-58. https://doi.org/10.1111/jzs.12041

Costa WJEM, Amorim PF, Mattos JLO (2012) Species delimitation in annual killifishes from the Brazilian Caatinga, the Hypsolebias flavicaudatus complex (Cyprinodontiformes: Rivulidae): implications for taxonomy and conservation. Systematics and Biodiversity 10: 71-91. http://dx.doi.org/10.1080/14772000.2012.664177
Costa WJEM, Amorim PF, Mattos JLO (2017) Molecular phylogeny and timing of diversification in South American Cynolebiini seasonal killifishes. Molecular Phylogenetics and Evolution. https://doi. org/10.1016/j.ympev.2017.07.020

Costa WJEM, Brasil GC (1990) Description of two new annual fishes of the genus Cynolebias (Cyprinodontiformes: Rivulidae) from the São Francisco basin, Brazil. Ichthyological Exploration of Freshwaters 1: $15-22$.

Costa WJEM, Brasil GC (1991) Three new species of Cynolebias (Cyprinodontiformes: Rivulidae) from the São Francisco basin, Brazil. Ichthyological Exploration of Freshwaters 2: 55-62.

Costa WJEM, Brasil GC (1993) Two new species of Cynolebias (Cyprinodontiformes: Rivulidae) from the São Francisco basin, Brazil, with notes on phylogeny and biogeography of annual fishes. Ichthyological Exploration of Freshwaters 4: 193-200.

Costa WJEM, Lacerda MTC, Brasil GC (1990) Description de deux nouvelles espèces du genre Cynolebias du bassin du Rio Tocantins (Cyprinodontiformes, Rivulidae). Revue Française d'Aquariologie et Herpetologie 17: 9-14.

Costa WJEM, Ramos TPA, Alexandre LC, Ramos RTC (2010) Cynolebias parnaibensis, a new seasonal killifish from the Caatinga, Parnaíba River basin, northeastern Brazil, with notes on sound producing courtship behavior (Cyprinodontiformes: Rivulidae). Neotropical Ichthyology 8: 283-288. https://doi.org/10.1590/S167962252010000200006

Hoedeman JJ (1958) The frontal scalation pattern in some groups of toothcarps (Pisces, Cyprinodontiformes). Bulletin of Aquatic Biology 1: $23-28$.

Taylor WR, Van Dyke GC (1985) Revised procedures for staining and clearing small fishes and other vertebrates for bone and cartilage study. Cybium 9: 107-109. http://sfi.mnhn.fr/cybium/numeros/1985/92/01-Taylor\%5b92\%5d107-119.pdf

Wilson EO (1985) The biological diversity crisis: a challenge to science. Issues in Science and Technology 2: 20-29. https://doi. org/10.2307/1310051

Wourms JP (1972) Developmental biology of annual fishes: III. Pre-embryonic and embryonic diapause of variable duration in the eggs of annual fishes. Journal of Experimental Zoology 182: 389-414. https://doi.org/10.1002/jez.1401820310 